\title{
5
}

\section{The Resistance of SMEs in Adopting Social Media: TOE Model}

\author{
Dyah Sugandini ${ }^{1}$, Mohamad Irhas Effendi, and Yuni Istanto \\ Management Department, Universitas Pembangunan Nasional "Veteran" Yogyakarta, Indonesia \\ \1dini@upnyk.ac.id
}

\begin{abstract}
This study aims to analyze the resistance to adoption of social media technology in SMEs in Yogyakarta. This research was conducted through a survey of respondents in SMEs using a questionnaire. The number of respondents in this study was 150 SMEs. Data analyser using SEM-PLS. The results of this study indicate that adoption resistance is influenced by manager support, organizational readiness and knowledge of SME managers. Manager support is the most substantial determining factor for SMEs in adopting the technology. The contribution of this research is to add theoretical support to adoption resistance. The resistance to social media adoption in SMEs is unique because the adoption of social media technology is needed during difficult times such as during the Covid-19 pandemic, but many SMEs do not want to adopt it.
\end{abstract}

Keywords: adoption, resistance, attitudes, manager support, organizational readiness, knowledge

\section{Introduction}

The development of the Internet and its related technologies, such as platforms social media, have also rapidly changed the way people communicate with one another. Today's consumers prefer to use online channels to traditional channels (Aspasia \& Ourania 2014). In the last two decades, more and more companies and companies have adopted electronic communication

(C) The Author(s) 2020

Sugandini, D., Irhas Effendi, M., Istanto, Y., (2020). The Resistance of SMEs in Adopting Social Media: TOE Model. In Ljupka Naumovska (Ed.), COVID-19 - Reshaping Marketing and Communications (pp.44-53). Proud Pen. https://doi.org/10.51432/978-1-8381524-7-5_5 
to carry out their marketing activities, thus providing a platform for $e$-marketing to grow at a faster rate. Social media has revolutionized the way marketing activities are carried out (Ndekwa \& Katunzi, 2016). Information Systems (IS) has many benefits for the organization, namely being able to increase performance, productivity, and organizational growth. Information Systems not only make employee tasks more straightforward, more comfortable to perform, and more standardized, they also assist stakeholders and managers in making increasingly competitive strategic decisions that impact the overall vision, mission, and results of the organization. The Technology Organization Environment (TOE) is a general framework that identifies various factors that influence organizational technology adoption (Chong \& Olesen, 2017). TOE is a company-level theory (Baker, 2012). The TOE framework is based on the concept which states that technology, organization, and the environment are factors that must be considered for companies when deciding to adopt innovations. Technological factors include relative advantages, complexity, compatibility, information technology capabilities and technological competencies (Seethamraju, 2015). Organizational factors refer to the size of the organization, organizational readiness, and employee attitudes towards technology and ownership type (Jackson et al., 2013;). Environmental factors include competitive pressure, pressure from trading partners, support from the government and environmental dynamics (Tsai et al., 2013).

SMEs are an essential component of a country in poverty alleviation and are significant contributors to the economic development of many nations (Muriithi, 2017). Smaller companies make it possible to create more jobs. Thomason, Simendinger, and Kiernan (2013) note that small companies are an intrinsic part of the economy that have contributed significantly to the success of the country's economy. Senff, Cavalho, Veiga, Duclos, and Pancote (2015) also emphasized that small businesses account for more than half of all companies and jobs in developed countries. Also, small firms are an essential source of income, accounting for a large number of industrial jobs in developing countries (Hyder \& Lussier, 2016). SMEs face tremendous challenges in their pursuit of technological innovation and their survival often depends on the use they make of information systems to develop new organizational models, compete in new markets or improve their internal and external communication relationships. Information systems are considered as important and rapidly evolving technological innovations that provide opportunities for businesses to increase their efficiency and effectiveness and even gain a competitive advantage (Porter, 2012). Compared to big companies, small businesses have been slow to adopt technological innovations.

On the other hand, one of the main criticisms of technology adoption research is that adoption is primarily viewed as a dichotomous outcome (adoption or not adoption). However, the adoption versus non-adoption approach does not fully explain technology adoption. This research takes the side of adoption rejection. Although reports suggest that social media does enhance the development of SMEs, there is still little empirical evidence on their adoption and use of this category of companies (Abeysinghe, 2013). This study aims to analyze the resistance to social media adoption in SMEs in Yogyakarta. Initial exploratory studies conducted by researchers show that most SMEs have not adopted digital marketing even though they desperately need this technology as a solution to recovering sales during the Covid-19 pandemic. This research is also important to do to answer the question of why resistance SMEs to adopt social media? Although SMEs know they need this technology. Information about the factors inhibiting the adoption of social media is also urgently needed to help SMEs transact successfully through digital marketing platformse. 


\section{Literature Review}

\subsection{Technology Adoption Resistance}

The leading technology adoption behavior theory finds the tendency of companies to reject or adopt information technology based on attitudes and beliefs. Planned behavior theory (TPB) is most commonly identified as predictive behavior theory (Ajzen, 1991). TPB from Ajzen's (1991) postulates that attitude correlates in influencing behavioral intention. Rogers' (2003) Diffusion of Innovation Theory minimizes the uncertainty of technology adoption behavior when introducing technology as a new way of solving complex problems. Another form of resistance or rejection of innovation was put forward by Joseph (2010). There are two forms of resistance, namely: active resistance and passive resistance. Active rejection occurs when an individual makes a decision not to adopt an innovation. Rejection usually occurs in operational resistance conditions. Rejection occurs when an individual processes available information and decides that he will not adopt an innovation. Forms of active rejection Another form of resistance or rejection of innovation was put forward by Joseph (2010). The second form of active denial is postponement. Procrastination occurs when an individual decides to delay the adoption of an innovation. An innovation delayer will wait for the right time to adopt a design. Passive resistance usually occurs more smoothly than active resistance. Passive resistance occurs in two ways, namely: first, there is no attention and second, not realizing there is an innovation. Interested individuals are usually aware of innovations but do not pay attention to these new innovations. Meanwhile, unaware individuals are individuals who do not have knowledge of innovations and even these individuals never know of existing innovative products (Sugandini et al., 2019).

\subsection{Attitude}

A more contemporary definition of an attitude refers to someone who has an affective and instrumental evaluation of behavior done. The benefit of the concept of attitude allows researchers to examine not only individual preferences but also social and cultural group dispositions and preferences. The formation of individual attitudes comes from information obtained by reviewing the actions of others. TPB is one of the most researched and influential theories used to explain attitudes towards technology, positive subjective norms for general use and the value of technology (Wright, 2017). If a company believes that a particular technology has desirable attributes that enhance their performance, they are likely to develop favourable attitudes towards its use. Perceived benefits are factors that can influence a company's intention to adopt the use of new Internet technologies (Alford \& G, 2015). Praveena and Thomas (2014) and Shen (2015) agree that attitude is an important factor influencing the intention to continue using Web technology. That knowledge of technical or technical knowledge will moderate the relationship between the use of social media marketing and the intention to continue to use social media marketing. Matikiti, Mpinganjira \& Roberts-Lombard (2018) conducted a study to determine the factors that influence attitudes towards the adoption of social media marketing by travel agencies and tour operators in South Africa. This research adopts a quantitative approach through the use of a questionnaire. The results showed that managerial support and managerial level of education were two main internal factors that influenced attitudes towards the use of social media marketing. Praveena and Thomas (2014) and Shen (2015), who concluded that there is a positive relationship between attitude and intention to continue using social media sites. Praveena and Thomas (2014) and Shen (2015) agree that attitude is an important factor influencing the intention to continue using Web technology. That knowledge of technical or technical knowledge will moderate the relationship between the use of social media marketing and the intention to continue to use social media marketing. According to El-Gohary (2012), inadequate technical knowledge is one of the main obstacles to adoption e-commerce among SMEs.

Hypothesis 1: Attitudes influence resistance to adoption social media 


\subsection{Management Support}

Technology adoption relies on the acceptance of information technology by SME leaders. If leadership does not see technology as useful or does not understand its potential, corporate leaders are reluctant to adopt it. The problems affecting technology adoption also have to do with the organization itself. Current technologies used in organizations can simplify or hinder the adoption process. The challenge emphasizes the ambiguity of technology investment and adoption processes in SMEs. More critical is the challenge of investing in and adopting the right technology for organizations to reduce managers' perceptions of control, self-confidence, and effort (Pavlou \& Fygenson, 2006). The results of research by Matikiti et al. (2018) show that managerial support affects attitudes towards the adoption of social media marketing. This means that if top management supports the idea of adopting new technology, the attitude of the entire organization towards the adoption of the latest technology will be positive. This is consistent with previous studies: Dahnil et al. (2014) concluded that top management influences attitudes towards project adoption e-commerce, while Matikiti et al. (2012) found that managerial support influences the adoption and implementation of initiatives ecommerce and Internet technology. Initial research conducted by researchers shows that SMEs managers are not yet supportive of adopting social media. Most of SMEs managers are still afraid to adopt because they are not sure about the benefits of social media. So the hypotheses proposed in this study are:

Hypothesis 2: Top management support affects the attitude of social media adoption.

\subsection{Organizational Readiness.}

The technology context includes the characteristics and usefulness of innovative technology; Organizational context includes internal problems within the company, such as management, employees, products and services, and the environmental context related to competitors and business partners (Piaralal et al., 2015). The TOE framework is widely used in the adoption of various innovative and proven technologies (Chiu et al., 2017). Chang (2010) defines organizational readiness as the availability of the company's financial and human resources. Pearson and Grandon (2005) note organizational readiness is the main reason technology adopters differ from nonadopters. Kloviene and Gimzauskiene (2009) note that environmental problems are important for the continuity of an organization is facing the environment so that it affects technology choices and the perceived benefits of information technology. Chong \& Olesen (2017) found that technology readiness which includes strong support for information technology infrastructure, perceived direct benefits, top management support, and competitive pressures, affect information technology adoption.

Hypothesis 3: Technology readiness affects attitudes to adopt social media

\subsection{Knowledge of SME Managers}

Galliers \& Leidner (2014) states that organizations established with standard operating procedures, clear targets, and transparent management policies can better adopt and implement information system technology. Than organizations have less clear business and information technology strategies. Thong (1999) points out the importance of information systems knowledge from CEOs and CEO innovations as key elements of technological innovation adoption. Executives and managers take on many different roles in SME organizations, even though managers in SMEs do not have knowledge or experience related to new information technology. These constraints have a negative impact on the SME's technology adoption rate, leaving them behind from larger organizations. Hugoson, Magoulas, \& Pessi (2010) said that knowledge is exposure to the existence of technology and understanding its function, which will form a favorable attitude. According to Awa et al. (2010), In the context of technology adoption, SMEs have the right skills to increase the knowledge and ability of SME executives in evaluating technology to improve technology adoption investment decisions. Chong et al., 2014; Ghobakhloo et al., 2011 showed that the characteristics of CEOs related to information technology knowledge 
are the determinants of SMEs in becoming technology. Molla and Licker, (2005) based on the research results, the most significant element of the organizational context in adopting technology, one of which is CEO knowledge. The technology context is described as the technical knowledge required to implement social media marketing (Matikiti et al., 2018); Chandra \& Kumar (2018)

Hypothesis 4: Knowledge of SME managers affects attitudes toward adopting social media.

\subsection{The Research Model}

The research model proposed in this study can be seen in Figure 1.1

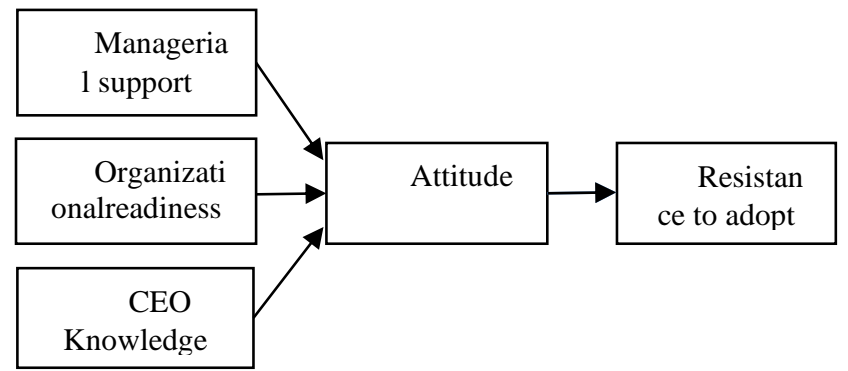

Figure. Model resistance to adoption of social media

\section{Research Methodology}

This study is a survey involving 150 SMEs in Yogyakarta. This study uses a questionnaire as a data collection tool. The questionnaire was adopted from Maltikiti et al. (2018) and Chamdar \& Kumar (2018). Data analysis techniques using structural equation modelling with Partial Leat square software 3.2.8. the results of validity and reliability testing indicate that not all instruments used are valid and reliable. The $\mathrm{X}_{21}$ and $\mathrm{Z}_{14}$ instruments were removed from the model because they had a value of less than 0.7 and invalid. The results of the reliability test after removing the items $\mathrm{X}_{21}$ and $\mathrm{Z}_{14}$ can shown support the reliability of the items used in this study.

\section{Finding and Discussion}

\subsection{Characteristic Respondents}

Characteristics of survey respondents are shown in Table 1. Most of the respondents are owners and managers of SMEs, and this is because in SMEs, usually, the owner is also the manager.

Table 1.

Characteristics of respondents

\begin{tabular}{ccc}
\hline Characteristics & & Percentage \\
\hline \multirow{2}{*}{ Gender } & Male & $46 \%$ \\
& Female & $54 \%$ \\
Age of Respondents & $\leq 30$ & $24 \%$ \\
& $30-39$ & $27 \%$ \\
Position in business & $40-49$ & $23 \%$ \\
& $\geq 50$ & $26 \%$ \\
& Owner & $34 \%$ \\
& Manager & $15 \%$ \\
& Owner and Manager & $49 \%$ \\
Type of Business & Others & $2 \%$ \\
& Fashion & $34 \%$ \\
& Culinary & $3 \%$ \\
& Crafts & $55 \%$ \\
& Others & $8 \%$ \\
\hline
\end{tabular}




\subsection{Results of Research Data Analysis}

Table 4 shows the results of the relationship between the variables studied. The research hypotheses put forward in this study are all accepted. Acceptance of the hypothesis can be seen from a p-value smaller than 0.05 .

Table 2.

Path analysis results

\begin{tabular}{lccccc}
\hline & $\begin{array}{c}\text { Original } \\
\text { Sample }(\mathrm{O})\end{array}$ & $\begin{array}{c}\text { Sample } \\
\text { Mean (M) }\end{array}$ & $\begin{array}{c}\text { Standard } \\
\text { Deviation } \\
(\text { STDEV) }\end{array}$ & $\begin{array}{c}\text { T } \\
\text { Statistics }\end{array}$ & P Values \\
\hline Attitude $\rightarrow$ Resistance to Adopt Social & 0.620 & 0.622 & 0.052 & 11.869 & 0.000 \\
Media & -0.123 & -0.130 & 0.065 & 2.884 & 0.049 \\
CEO Knowledge $\rightarrow$ Attitude & -0.538 & -0.534 & 0.059 & 9.140 & 0.000 \\
Manager Support $\rightarrow$ Attitude & -0.128 & -0.133 & 0.063 & 2.023 & 0.044 \\
Readiness Organization $\rightarrow$ Attitude & & R Square & & Adjusted R Square \\
& & 0.684 & & 0.680 \\
Adoption Social Media & & 0.695 & & 0.683 \\
Attitude & &
\end{tabular}

\section{Discussion}

The results of the research showed that all hypothesis is supported. Resistance to the adoption of social media in SMEs is due to the lack of support from top managers, SMEs unpreparedness in adopting information technology, and lack of knowledge of managers about social media technology. This causes SMEs in Yogyakarta to not be able to adopt social media technology for marketing their products. According to Matikiti et al., (2018), managerial support is very important for the effectiveness of information systems in SMEs and is an obstacle to the acceptance of e-business in SMEs. Lin (2014) also found that top management support has a positive influence on technology adoption cloud computing so that the low support for SME managers means that the attitude towards low adoption and the decision to adopt social media technology from these SMEs is low. The results of this study support Dahnil et al. (2014); Matikiti et al. (2018) who show that managerial support affects attitudes towards the adoption of social media marketing (Matikiti et al., 2012). The readiness of SMEs in adopting social media technology also shows unfavourable results. Yogyakarta is not ready to adopt social media technology. SMEs in Yogyakarta is not yet able to provide a human resource that can handle social media applications. SMEs owners and managers feel that their organization is not ready to fully adopt social media platforms. Information about marketing through social media platforms not well understood, so the attitude of SME managers is less responsive to social media. Many SMEs complain about fraud through social media that they experience and their organizations are not ready to handle it. This causes them to be reluctant to adopt social media technolog (Support by Piaralal et al., (2015); Chiu et al., (2017); Pearson and Grandon 2005). Chong \& Olesen (2017) also show that technology readiness which includes technology infrastructure and perceived benefits, directly affects the adoption of information technology.

The knowledge of SMEs owners and managers about social media technology is still low. Many SME managers and owners do not understand the use of social media platforms to market their products. Knowledge of how SME managers do not yet understand social media works, about the benefits of social media and the information technology used. Low knowledge of social media technology causes low attitudes towards adoption. The low attitude causes the decision to adopt social media technology to be low. SMEs tend to be 
resistant to adopting social media. The results of this study support Galliers \& Leidner (2014); Thong (1999) which shows that the importance of information systems knowledge from CEOs on the adoption of technological innovations. Hugoson, Magoulas, \& Pessi (2010) also state that management knowledge will form a favorable attitude. Awa et al. (2010); Chong et al., (2014); Ghobakhloo et al., 2011 showed that CEO knowledge is a determinant of technology adoption in SMEs (Matikiti et al., 2018); Chandra \& Kumar (2018).

\section{Conclusion}

This research results in the findings that many SMEs in Yogyakarta during the Covid-19 pandemic are not yet willing to adopt social media technology. The main reason that emerges is that SMEs managers have not supported the adoption of social media technology. Several obstacles cause SME managers not to adopt them because they feel they are not ready, they do not have human resources to manage, and the technology infrastructure is also inadequate. The manager's lack of knowledge about the benefits of using social media technology is also the reason why SMEs do not want to adopt social media. The results of this study indicate that the four proposed hypotheses are accepted.

\subsection{Contribution and Suggestions for Future Research}

This study was conducted during the Coronavirus pandemic. During the Covid-19 pandemic, SMEs are in a challenging position in carrying out operations and marketing of their products because there is work from home regulations. The results of this study indicate that although social media technology is very helpful for SMEs during the Covid-19 pandemic, this technology has not been fully adopted by SMEs. This is because there is no support from SME managers, SME organizations are not ready to adopt social media technology and the risks it poses, and lack of knowledge of SMEs managers. This research contributes to the theory which states that not all innovation adoptions are well accepted by its users, even though the technology is indeed prepared to solve the problem.

Future research is expected to be able to explore further about the rejection of the adoption of social media technology with the characteristics of SMEs managers more fully. Such as the level of education, socio-economic background, the number of assets owned and the type of production process that is carried out. For the type of production process carried out is related to whether SMEs carry out the production process continuously or only carry out production processes based on orders. This could lead to findings that differ from this research and will add new insights to research on the resistance to the adoption of social media technologies.

\section{References}

Abeysinghe, G., Aisha, Y., \& Alsobhi. (2013). Social media readiness in small businesses.International Conference on Information System (IADIS 2013). At Lisbon, Portugal.

Ajzen, I. (1991). "The theory of planned behavior". Organizational Behavior and Human Decision Processes, 50(2), 179-211.

Alford, P., \& Page, S.J. (2015). "Marketing technology for adoption by small business".The Service Industries Journal 35(11/12), 655-669. https://doi.org/10.1080/0264 2069.2015.1062884. 
Aspasia, V., \& Ourania, N. (2014). "Social media adoption and managers' perceptions".International Journal on Strategic Innovative Marketing 1, 61-73. https://doi. org/10.15556/IJSIM.01.02.001

Awa, H. O., Nwibere, B. M., \& Inyang, B. J. (2010). "The uptake of electronic commerce by SMEs: A meta-theoretical framework expanding the determining constructs of TAM and TOE frameworks". Journal of Global Business \& Technology, 6(1), 1-27.

Baker, J. (2012). The Technology-Organization-Environment Framework. information systemsTheory. Springer, Berlin.

Chandra, S., \& Khumar, K. N. (2018). "Exploring Factors Influencing Organizational Adoption of Augmented Reality in E-commerce: Empirical Analysis UsingTechnologyOrganization- Environment Model".Journal of Electronic Commerce Research, Vol 19, No 3,

Chang, K. P., \& Graham, G. (2010). "E-Business Strategy in Supply Chain Collaboration: An Empirical Study of B2B E-commerce Project in Taiwan". International Journal of Electronic Business Management. Vol. 10, Issue 2, pp, 101-112.

Chiu, Chui-Yu., Chen, Shi., \& Chen, Chun-Liang. (2017). "An integrated perspective of TOE framework and innovation diffusion in broadband mobile applications adoption by enterprises. International Journal of Management, Economics and Social Sciences. Vol. 6, Iss. 1, pp. 14-39.

Chong, Josephine L.L., \& Olesen, Karin (2017). "A Technology-Organization-Environment Perspective on Eco-effectiveness: A Meta-analysis". Australasian Journal of Information Systems. Vol 21, pp. 1-26.

Chong, A.Y.-L., Ooi, K.B., Bao, H., \& Lin, B. (2014). "Can e-business adoption be influenced by knowledge management? An empirical analysis of Malaysian SMEs". Journal of Knowledge Management. Vol. 18 No. 1, pp. 121-136.

Dahnil, M.L., Marzuki, K.M., Langgat, J., \& Fabeil, N.F. (2014). "Factors influencing SMEs adoption of social media marketing". Procedia-Social and Behavioral Sciences 148, 119 126. https://doi.org/10.1016/j.sbspro.2014.07.025

El-Gohary, H. (2012). "Factors affecting e-marketing adoption and implementation in tourism firms: An empirical investigation of Egyptian small tourism organisations". Tourism Management. Vol. 33(5), 1256-1269. https://doi.org/10.1016/j.tourman.2011. 10.013.

Galliers, R. D., \& Leidner, D. E. (2014). Strategic information management: challenges and strategies in managing information systems. United Kingdom, Routledge.

Ghobakhloo, M., Arias-Aranda, D., \& Benitez-Amado, J. (2011). "Adoption of e-commerce applications in SMEs", Industrial Management \& Data Systems, vol. 111, no. 8, pp. 12381269.

Hugoson, M.-A., Magoulas, T., \& Pessi, K. (2010). "The impact of enterprise architecture principles on the management of IT investments". Proceedings of the European Conference on Information Management \& Evaluation, 152-159.

Hyder, Shabir., \& Lussier, Robert. (2016). "Why businesses succeed or fail: a study on small businesses in Pakistan". Journal of Entrepreneurship in Emerging Economies. 8. 82-100. 10.1108/JEEE-03-2015-0020.

Joseph, R. (2010). "Individual Resistance to IT innovations," Communication of the ACM, vol 53no. 4. 
Kloviene, L., \& Gimzauskiene, E. (2009). "Performance measurement system changes according to organization's external and internal environment". Economics \& Management, 70-77.

Lin, H. F. (2014). "Understanding the determinants of electronic supply chain management system adoption: Using the technology-organization-environment framework". Technological Forecasting and Social Change. Vol. 86(1), pp. 80-92.

Matikiti, R., Afolabi, B., \& Smith, W. (2012). "An empirical evidence on the usage of internet marketing in the hospitality sector in an emerging economy and its relationship to profitability". International Review of Social Sciences and Humanities. Vol. 4(1), pp. 181197.

Matikiti, R., Mpinganjira, M., \& Roberts-Lombard. (2018). "Application of the Technology Acceptance Model and the Technology-Organisation-Environment Model to examine social media marketing use in the South African tourism industry". Journal of Information Management. 20. 10.4102/sajim.v20i1.790.

Muriithi, Samuel. (2017). "African Small and Medium Enterprises (Smes) Contributions, Challenges and Solutions". International Journal of Research \& Reflection in Management Science. 5. 13.

Ndekwa, A.G., \& Katunzi, T.M. (2016). "Small and medium tourist enterprises and social media adoption: Empirical evidence from Tanzanian tourism sector". International Journal of Business and Management. Vol. 11(4), pp. 71-80. https://doi.org/10.5539/ijbm. v11n4p71

Pavlou, P. A., \& Fygenson, M. (2006). "Understanding and prediction electronic commerce adoption: An extension of the theory of the planed behavior". MIS Quarterly. 30(1), 115143.

Pearson, J. M., \& Grandon, E. E. (2005). "An empirical study of factors that influence ecommerce adoption/non-adoption in small and medium sized businesses". Journal of Internet Commerce, 4(4), 1-21.

Piaralal, S. K., Nair, S. R., Yahya, N., \& Karim, J. A. (2015). "An integrated model of the likelihood and extent of adoption of green practices in small and medium sized logistics firms". American Journal of Economics. Vol. 5(2), pp. 251-258.

Porter, G. (2012). "Mobile phones, livelihoods and the poor in Sub-Saharan Africa: review and prospect", Geography Compass, vol. 6, no. 5, pp. 241-259.

Praveena, K. \& Thomas, S. (2014). "Continuance intention to use Facebook: A study of perceived enjoyment and TAM".International Journal of Industrial Engineering and Management 4(1), 24-29.

Rogers, E. (2003). Diffusion of innovations, $5^{\text {th }}$ ed., New York, NY: The Free Press.

Seethamraju, R. (2015). "Adoption of software as a service (SAAS) enterprise resource planning (ERP) systems in small and medium-sized enterprises". Information Systems Frontiers 17(3).

Senff, C., Carvalho, G., Veiga, C., Duclós, L., \& Pancote, A. (2015). "Enterprise architecture maturity stages: A cluster analysis in Brazilian small businesses". African journal of business management. 9. 501-512. 10.5897/AJBM2015.7799.

Shen, G.C. (2015). "How quality of life affects intention to use social networking sites: Moderating role of self-disclosure". Journal of Electronic Commerce Research 16(4), 276289. 
Sugandini, D., Effendi, M. I., Istanto., Y., Arundati, R., \& Rahmawati, E.D. (2019). Technology-Organization-Environment Model and Technology Acceptance Model in Adoption of Social Media Marketing on SMEs Tourism". Journal of Environmental Management and Tourism. Vol. 10, no. 4, pp. 878-885. DOI: https://doi.org/10.14505//jemt.10.4(36).19.

Thomason, S., Simendinger, E., \& Kiernan, D. (2013). "Several determinants of successful coopetition in small business". Journal of Small Business \& Entrepreneurship. 26. 15-28. 10.1080/08276331.2012.761800.

Thong, J. Y. (1999). "An integrated model of information systems adoption in small businesses". Journal of Management Information Systems. Vol. 15, no.4, pp.187-214.

Tsai, M. C., Lai, K. H., \& Hsu, W. C. (2013). "A study of the institutional forces influencing the adoption intention of RFID by suppliers". Information and Management. Vol. 50(1), pp. $59-65$.

Wright, A.D. (2017). "Few Companies Explore New Technologies".Society for Human Resource Management.

\section{Proud Pen}

(C) 2020 The Author(s). Licensee Proud Pen Limited. This chapter is distributed under the terms of the Creative Commons Attribution License (https://creativecommons.org/licenses/by/4.0/), which permits unrestricted use, distribution, and reproduction in any medium, provided the original work is properly cited.

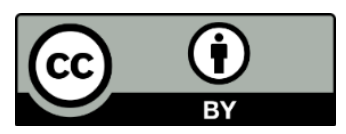

